\title{
Clinical, Biochemical and Radiological Factors Affecting the Prognosis of Neurological Deficit Improvement in Spinal Tuberculosis Patients at Hospitals of Sabah
}

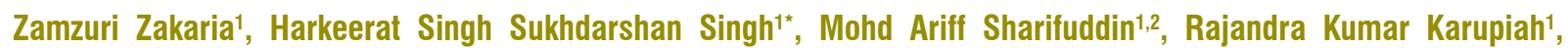
Mohd Adham Shah Ayeop', Naveen Vijayasingham³

\author{
1 Department of orthopaedics, \\ Traumatology and Rehabilitation, \\ Kulliyyah of Medicine, \\ International Islamic University Malaysia, \\ Kuantan, Pahang, Malaysia \\ 2 Department of Orthopaedics, \\ Faculty of Medicine, \\ Universiti Sultan Zainal Abidin, \\ Kampung Gong Badak, Terengganu, Malaysia \\ ${ }^{3}$ Department of Orthopaedics, \\ Traumatology \& Rehabilitation, \\ Hospital Tawau, Tawau, Sabah, Malaysia
}

\section{*Corresponding author's email: drkeerat@gmail.com}

Received: 28 December 2020

Accepted: 17 August 2021

Keywords: prognostic factor,

spine infection, spinal tuberculosis,

thoracolumbar spine

\section{ABSTRACT}

The incidence of spinal tuberculosis is highest in developing nations. We aimed to analyse the clinical, biochemical, and radiological parameters in spinal tuberculosis patients with significant neurological impairment in relation to their functional outcome. This cross-sectional study involved 224 patients who had been presented to three hospitals in Sabah from July 2017 to June 2018, with significant neurological impairment fulfilling the inclusion criteria were enrolled. Diagnosis of spinal tuberculosis was determined by clinical and radiological factors and confirmed with histopathology, micro bacteriology, and immunoassay. Patients with significant neurology received standard treatment protocol according to the middle pathway regime, anti-tuberculosis for the first three weeks, and were subjected to surgery if there was no improvement. Age, duration of symptoms, c-reactive protein (CRP), erythrocyte sedimentation rate (ESR), white cell count (WCC), thoracolumbar spine involvement, and presence of soft tissue collection were evaluated. Modified Barthel Index (MBI) was used to assess the functional outcome. After a year, 146 patients (65.1\%) had good functional outcomes and 78 patients had no significant improvement. On univariate analysis, there were no significant correlations between functional outcome and age ( $p>0.45)$; duration of symptoms ( $p>0.68)$; CRP ( $p>0.76)$; WCC ( $p>0.99)$; and presence of soft tissue collection $(p>0.21)$. High ESR $(p<0.008)$ and thoracolumbar lesions were associated with poor functional outcomes $(p<0.033)$. Higher ESR values and thoracolumbar lesions were associated with poor prognostic factors functional outcome in spinal tuberculosis patients. 


\section{INTRODUCTION}

Spinal Tuberculosis (TB) was first described by Percival Pott in 1979 as one of the most common forms of extrapulmonary tuberculosis. The number of reported cases has been rising ever since and its incidence is highest in developing countries. It accounts for about $2-15 \% \%$ of cases of TB, representing the most common target of osteoarticular TB (Snider et al., 2017; Yong et al, 2020). In Malaysia, there have been 25,713 cases recorded for tuberculosis in 2018 alone with an estimated incidence rate of 92 per 100000 cases. (WHO, 2013). While Tuberculosis cases associated with mortality is on the downtrend, their incidence is not decreasing in line with the global End TB Milestones. (lyawoo, 2004; WHO, 2015). While the state of Sabah accounts for $10 \%$ of the country's total population, it accounts for $20-30 \%$ of all Malaysian tuberculosis cases. (Goroh et al., 2020). Due to the proximity of the pathology to the spinal cord, spinal tuberculosis patients present with neurological deficits in up to $20-41 \%$ of patients (Jain, 2012). Thoracic spine accounts for the largest proportion (30.3 - 55.8\%) of spinal tuberculosis patients (Dharmalingam et al., 2004). It is a disease with variable symptoms, ranging from vague back pain to devastating neurological deficits. The presence of caseous granuloma, abscess, and tuberculous arachnoiditis exerted mechanical pressure on the cord or cauda equina leading to early paralysis. On the other hand, late paralysis is mainly due to the deformity of the spine. Thoracic spine accounts for the largest proportion (30.3 -55.8\%) of spinal tuberculosis patients (Dharmalingam et al., 2004).

Common investigations performed are the Mantoux test, white cell counts (WCC), erythrocyte sedimentation rate(ESR), c-reactive protein (CRP), whole spine $X$-rays, computed tomography (CT), and magnetic resonance imaging (MRI) scans. Early administration of medical chemotherapy supplemented with surgical debridement and stabilization remains the gold standard of treatment. Some recent studies focused on the clinical and radiological factors affecting neurological improvement in patients suffering from spinal tuberculosis (Sharma et al., 2017; Yao et al., 2017).

An Indian study looking into 312 patients with spinal tuberculosis concluded that the level of vertebrae involved, AIS (Asia Impairment Scale) grade at presentation and bowel and bladder symptoms and its duration to be significant demographic factors affecting the final neurological recovery. (Sharma et al,.2016). A study of 237 thoracic spinal tuberculosis patients undergoing surgery concluded that a shorter duration of symptoms (less than three months), fewer involved vertebrae (less than 2 levels) are favourable prognostic factors. (Yao et al., 2017).

Other reported causes of poor prognosis are poor nutritional status, low socioeconomic income, and other concurrent systemic diseases (Cao et al., 2018).

The current study looked into the three categories of factors to provide a holistic approach towards the patients by analysing the clinical, biochemical, and radiological factors that affect the functional outcome of spinal tuberculosis patients with neurological deficits. To identify factors that might predict a poor functional outcome recovery in spinal tuberculosis patients. These patients may require more aggressive rehabilitation to give them a better chance at achieving their best functional outcome recovery (Yong, 2020).

\section{MATERIAL AND METHODS}

This cross-sectional study was carried out in three hospitals in the state of Sabah, Malaysia comprising of Hospital Queen Elizabeth, Kota Kinabalu, Hospital Tawau, and Hospital Lahad Datu from August 2017 to August 2018. All newly diagnosed patients with spinal tuberculosis with significant neurological deficits were recruited into this study. There were 87 patients from Hospital Tawau, 80 
patients from Hospital Queen Elizabeth, and 69 patients from Hospital Lahad Datu. There was a total of 236 spinal tuberculosis patients with significant neurology deficits recruited. The criteria for the inclusion of patients to this study were age (between 19 and 64 years old), diagnosed with spinal tuberculosis either with histopathological analysis suggesting a granulomatous lesion, mycobacteriology, immunoassay suggestive of tuberculosis, or empirically treated for tuberculosis based on characteristic clinical and imaging criteria, and neurological deficit of Frankel A (complete absence of motor and sensory function), Frankel B (presence of sensation but no motor function), or Frankel C (presence of sensation with motor function of Medical Research Council (MRC) scale 2 to 3 ) and who had been treated surgically. Out of the 236 patients, six patients did not consent for the study, three patients did not complete their follow up, two patients were deceased due to unrelated fulminant sepsis and one patient was deceased due to a cardiopulmonary event. This resulted in a total of 224 patients were included in this study. Patients with multidrug-resistant tuberculosis, spinal lesion due to metastasis, pyogenic, or fungal origins, other injuries that limit movements and coordination, comorbidities that confound to poor activities of daily living were excluded from the study.

Once eligible, patients were asked to give written consent, and a proforma for each patient was filled up by the doctor in charge. This study was approved by the National Medical Research Register (NMRR) and Medical Research and Ethics Committee (MREC) with the following study ID NMRR-17-3124-39314.

The functional outcome was scored based on the Barthel Index, which was divided into 10 categories of activities of daily living, scoring from 0 to 3, with a maximum total of 20. Good functional outcome was taken as an improvement of 4 or more points, or a recovery to 12 or more points. Clinical parameters studied were age, gender, and duration of illness before the presentation. The patients' age was measured in years and defined as age at the commencement of treatment. The duration of symptoms was measured in weeks from the onset of the first symptom to the time of presentation. The biochemical parameters studied were WCC (x109), ESR $(\mathrm{mm} / \mathrm{Hr})$, and $\mathrm{CRP}(\mathrm{mg} / \mathrm{dL})$ levels on presentation.

Radiological data was taken from patients' spine plain radiographs and MR images. The parameters measured were spinal segment involvement, the number of vertebrae, the extension of the abscess into the spinal canal, and the extension of the abscess into the surrounding soft tissue.

Frankel scoring was determined based on the Frankel Grading System. Frankel A being an absence of motor or sensory function below the level of lesion, Frankel $B$ being an absence of motor function, but with some degree of sensitivity preserved below the level of the lesion, Frankel $\mathrm{C}$ being some degree of motor function but without practical usefulness.

During this study, the patients received tailored treatment for their spinal tuberculosis, either with anti-tuberculous chemotherapy alone following the "middle pathway" guidelines, or a combination of chemotherapy with surgical intervention. For surgical intervention, we predominantly performed debridement, posterior instrumentation, and titanium cage insertion. Anterior debridement, instrumentation, and fusion were reserved for mainly complex cervical lesions and rarely a combined anterior and posterior instrumentation. Frankel scoring and Modified Barthel Index were compared at presentation and one year post-treatment.

The data collected were tabulated, and statistical analysis was performed using SPSS software (version 15.0E; IBM, Armonk, NY, USA). Regression logistic models were used to compare the clinical, biochemical, and radiological parameters against the functional 
status improvement. Demographic data were calculated in percentages, mean, and standard deviations. The individual prognostic factors were then calculated using the chi-square test for the categorical data, and the student T-test for the numerical data. Significant parameters were then analysed with a multiple logistic regression model. A p-value of $<0.05$ was taken as statistically significant.

\section{RESULTS}

There was a total of 224 patients who received treatment and enrolled in the study. Demographic distribution showed 116 (51.8\%) male and 108 female (48.2\%) patients (Figure 1) with ages ranging from 19 to 64 years old. The mean duration of symptoms was 4.2 weeks. White cell counts (WCC) ranged from $4.6 \times 105$ to $12.7 \times 105$ with a mean of $8.6 \times$ 105. ESR values ranged from 36 to 132 . CRP levels ranged from 3.2 to 60.9 with a mean of 32.6. Levels of vertebrae involved ranged from 1 - 6 levels with a mean of 3.3 vertebrae. Barthel index on presentation ranged from 2 17 with a mean of 15 and a standard deviation of 3.6 (Table 1).

Table 1 Demographic data of patients $(n=224)$

\begin{tabular}{lcc}
\hline Variables & Range & Means (SD) \\
\hline $\begin{array}{l}\text { Age (years) } \\
\text { Duration of } \\
\text { symptoms (weeks) }\end{array}$ & $19-64$ & $43.8(11.3)$ \\
$\begin{array}{l}\text { White cell count } \\
\left(\times 10^{5}\right)\end{array}$ & $4.6-12.7$ & $8.2(2.3)$ \\
$\begin{array}{l}\text { ESR (mm/hr) } \\
\text { CRP }\end{array}$ & $36-132$ & $83.8(28.4)$ \\
$\begin{array}{l}\text { Involvement } \\
\text { of vertebrae } \\
\text { (number) }\end{array}$ & $3.2-60.9$ & $32.6(16.9)$ \\
$\begin{array}{l}\text { Barthel index on } \\
\text { presentation }\end{array}$ & $1-6$ & $3.3(1.4)$ \\
\hline
\end{tabular}

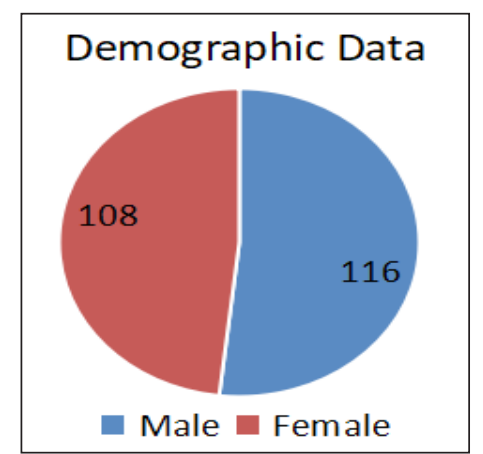

Figure 1 Demographic data of patients $(n=224)$

The degree of abscess extension showed 133 (59.4\%) patients had extension into the soft tissue and 91 (40.6\%) patients had no evidence of extension. For Frankel scoring, the inclusion criteria looked into patients with Frankel $C$ or worse, Frankel $A$ had 5 patients (2.2\%), Frankel B with 47 patients (21.0\%) and Frankel C with 172 patients (76.8\%). A total of 129 patients required surgical intervention, in which 109 (91.6\%) underwent debridement, posterior instrumentation and cage insertion, eight (6.7\%) required debridement, anterior instrumentation, and cage insertion, and two (1.7\%) had a combined anterior and posterior debridement and instrumentation. A total of 95 patients were treated conservatively with chemotherapy. Out of the 224 patients, 146 patients (65.1\%) had good functional outcomes and 78 patients $(34.9 \%)$ had no significant improvement in functional outcome (Table 2).

Table 2 Presentations, surgical interventions and outcomes

\begin{tabular}{lc}
\hline Variables & $\boldsymbol{N}(\%)$ \\
\hline Extension of tuberculous abscess & \\
Yes & $133(59.4 \%)$ \\
No & $91(40.6 \%)$ \\
Frankel score on the presentation & \\
A & $5(2.2 \%)$ \\
B & $47(21 \%)$ \\
C & $172(76.8 \%)$ \\
D & $0(0 \%)$ \\
E & $0(0 \%)$ \\
Required surgical intervention & \\
Yes & $129(57.6 \%)$ \\
No & $95(42.4 \%)$ \\
Outcome & \\
Good functional outcome & $146(65.1 \%)$ \\
No significant improvement & $78(34.8 \%)$ \\
\hline
\end{tabular}


Patients with a good functional outcome had a mean age of 45.8 years, whereby those with a poor functional outcome had a mean age of 48.2 years. There was no statistically significant $(p=0.713)$ difference in age between the patients of the two groups. The relationship between patients' age and their functional outcome was also found to be not significant $(p=0.255)$. Patients with a good functional outcome had a mean duration of symptoms of 4.4 weeks, and a mean of 4.2 in the poor outcome group. Similar to patients' age, no statistically significant $(p=0.306)$ relationship between the duration of symptoms and the functional outcome of patients was observed.

There was no significant difference in all three biochemical parameters between patients with a good functional outcome and those without improvement. The functional outcome was also found not related to patients' WCC and CRP levels $(p=0.679$ and $p$ $=0.572$, respectively). On the other hand, the level of ESR was observed to have a significant ( $p=0.019$ ) relationship with the functional outcome of patients.
For spinal segments involved the good functional outcome had the majority of the patients involving the thoracic level with 65 patients, followed by 50 patients involving the lumbar region, 28 with thoracolumbar region involvement and three patients with cervical lesions. In the no improvement group the majority of the lesions were in the thoracolumbar with 28 patients followed by thoracic and thoracolumbar lesions with 22 patients each, eight patients with cervical lesions and one patient with a cervicothoracic lesion.

The number of vertebrae involved was 2.92 in the good functional outcome group versus 3.00 in the group with no functional outcome. Extension of the abscess into the spinal cord was observed in 83 patients with good functional outcomes compared to 50 patients from the no improvement group. Extension of the abscess into the soft tissues was seen in 130 patients from the good functional outcome group compared to 64 patients from the no improvement group (Table 2).

Table 2 Comparison of variables between the patients with a good functional outcome and those without improvement $(n=224)$

\begin{tabular}{|c|c|c|c|}
\hline Variables & $\begin{array}{l}\text { Good functional outcome } \\
\qquad \begin{array}{c}(n=146) \\
\text { Mean ( } \pm \text { SD) }\end{array}\end{array}$ & $\begin{array}{l}\text { No improvement of } \\
\text { functional outcome } \\
\qquad(n=78) \\
\text { Mean ( }( \pm \text { SD) }\end{array}$ & $X^{2}$ \\
\hline
\end{tabular}

Sex

Male
Female
Age
Duration of symptoms
ESR
CRP
WCC
Spinal segment involvement

43
35
$45.8(13.7)$
$4.4(2.1)$
$81.6(31.9)$
$426.5(116.6)$
$8.1(2.4)$

$8.1(2.4)$
73

73

$\begin{array}{lll}48.2(10.8) & 0.375 & 0.713 \\ 4.2(2.8) & 0.214 & 0.834 \\ & & \\ 88.0(35.6) & 0.388 & 0.703 \\ 409.0(164.9) & 0.262 & 0.797 \\ 7.7(1.8) & 0.332 & 0.744 \\ & 14.249 & 0.007\end{array}$


Borneo Journal of Medical Sciences 15 (3) September, 2021: $37-47$

$\begin{array}{lll}\text { Thoracic } & 65(74.7 \%) & 22(25.3 \%) \\ \text { Thoracolumbar } & 28(56.0 \%) & 22(44.0 \%) \\ \text { Lumbar } & 50(66.7 \%) & 25(33.3 \%) \\ \text { Cervical } & 3(27.3 \%) & 8(72.7 \%) \\ \text { Cervicothoracic } & 0(0.0 \%) & 1(100 \%)\end{array}$

Number of vertebrae

Extension of the abscess into the spinal cord
Yes
No

Extension of the abscess into soft tissue
Yes
$130(67.0 \%)$
$64(33.0 \%)$
No
$16(53.3 \%)$

$50(37.6 \%)$

$28(30.8 \%)$

The Simple Logistic Regression analysis is a univariable analysis that gives a preliminary idea of which variables are identified as the potential significant associated factor. From the analysis, four variables were found to have a significant value $<0.25$. The potential significant variables were ESR, spinal segment involved, number of vertebrae and extension of the abscess into soft tissue. All of these variables were included in Multiple Logistic Regression analyses and any variables with $p<0.05$ would be considered significant factors associated with functional outcomes. However, three variables were found to be significant i.e. ESR, thoracolumbar spinal segment involved and the number of vertebrae $(p<0.05)$. ESR showed significant association with the functional outcome with an odds ratio of 1.02 and a confidence interval was 1.00 - 1.02. Thoracolumbar spinal segment involvement had an odds ratio of 3.31 with a confidence interval of $1.44-7.54$. The number of vertebrae involved had an odds ratio of 0.83 with a confidence interval of $0.56-0.97$ (Table 3).

Table 3 Associated factors of functional outcomes in patients

\begin{tabular}{|c|c|c|c|c|}
\hline \multirow[t]{2}{*}{$\begin{array}{l}\text { Variables } \\
\text { Crude Odds Ratio }(95 \% \mathrm{Cl})\end{array}$} & \multicolumn{2}{|l|}{$\begin{array}{l}\text { Simple Logistic } \\
\text { Regression }\end{array}$} & \multicolumn{2}{|l|}{$\begin{array}{l}\text { Multiple Logistic } \\
\text { Regression }\end{array}$} \\
\hline & $p$-value & $\begin{array}{c}\text { Adjusted } \\
\text { Odds } \\
\text { Ratio } \\
(95 \% \mathrm{Cl}) \\
\end{array}$ & $p$-value & \\
\hline Age & $0.99(0.96,1.01)$ & 0.255 & - & - \\
\hline Duration of symptoms & $1.06(0.94,1.20)$ & 0.306 & - & - \\
\hline ESR & $1.01(1.00,1.02)$ & 0.019 & $1.02(1.004,1.026)$ & 0.008 \\
\hline CRP & $1.00(0.99,1.00)$ & 0.572 & & \\
\hline WCC & $0.99(0.98,1.00)$ & 0.679 & & \\
\hline \multicolumn{5}{|l|}{$\begin{array}{l}\text { Spinal segment } \\
\text { involvement }\end{array}$} \\
\hline Thoracic & & 0.082 & & 0.082 \\
\hline Lumbar & $1.48(0.74,2.92)$ & 0.262 & $1.03(0.47,2.24)$ & 0.939 \\
\hline Thoracolumbar & $2.32(1.10,4.85)$ & 0.025 & $3.31(1.44,7.54)$ & 0.004 \\
\hline
\end{tabular}


Number of vertebrae

$0.83(0.68,1.01)$

$0.74(0.42,1.30)$

0.293

Extension of the abscess into the soft tissue

Yes

No

$1.78(0.82,3.87)$

0.147

$1.77(0.764,4.098)$

0.179

\section{DISCUSSION}

This study was conducted to determine the clinical, biochemical, and radiological factors affecting neurological improvement in thoracolumbar tuberculosis patients. From the clinical parameters, age and duration of symptoms did not show any statistical significance with the functional outcome in our study population. The mean age of 43.8 was comparable to other study populations which cited the age ranging from 45 to 60 years in their incidence of spinal tuberculosis (Held et al., 2017). In the current study, there was no statistical difference between the age among patients with a good functional outcome and those without improvement following treatment. Studies looking into spinal tuberculosis patients in Korea and India have reported younger age as a good predictor of outcome (Park et al., 2007; Sharma et al., 2016). Our study did not observe similar findings due to a more elderly population recruited in comparison to the other studies. On a further note, Bacille-Calmette-Guerin (BCG) vaccination programme was introduced in the country in 1961. Hence, tuberculosis infection is rarely seen in our younger population. The duration of symptoms varied from one to 13 weeks with a mean of 4.2 weeks corresponding to approximately a month. This is attributed to the slow and insidious onset of the pathophysiology of tuberculosis. Usually, the primary site of infection is not clinically captured early and requires seeding into the spine before symptoms manifest. Early bony changes require some time to develop and might be easily missed by untrained primary care physicians (Ferrer et al., 2012). Another possible reason for the delay of presentation up to 13 weeks could be attributed to the geographical nature of the state of Sabah being mountainous with poor access to the rural areas. There was no significant difference with regards to the duration of symptoms between patients with a good functional outcome and those without improvement $(p=$ 0.834). However, a study evaluating medically treated patients with spinal tuberculosis concluded that a long duration of illness (more than six months) was associated with a poor prognosis (Sharma et al., 2017).

In this study, erythrocyte sedimentation rate, thoracolumbar lesions, the number of vertebrae involvement, and the extension of the abscess into the soft tissue were found to have $p$-values of $<0.250$ when analysed with the simple logistic regression. All four variables were included in the multiple logistic regression. Variables with $p<0.05$ were considered as significant factors associated with the functional outcome. Erythrocyte sedimentation rate showed a significant relationship with the functional outcome ( $p=0.008)$, with a one-unit increment of ESR had 1.02 times higher odds to have a poor functional outcome. Patients with a thoracolumbar lesion had 3.31 times higher odds to have a good functional outcome 
compared to patients with a thoracic lesion ( $p$ $=0.004$ ). The number of vertebrae involvement also showed a significant relationship with the functional outcome $(p=0.031)$.

Biochemical parameters such as the WCC, ESR, and CRP may be elevated but they are not specific for spinal tuberculosis. A Taiwanese study shared similar findings on the clinical features and outcomes in spinal tuberculosis. The study reported no significant correlation between the functional outcome of patients and the value of WCC, ESR, or CRP (Su et al., 2010; Wang et al., 2012). However, ESR had a different take in the current study, showing a significant relationship with the functional outcome after being analysed with multiple logistic regression $(p=0.008)$. The patients who had an increment of one unit of ESR had 1.02 times higher odds to have a poor functional outcome. This is likely due to the extensive pathology with more bony structural destruction and soft tissue abscess collection. A higher level of ESR had also been associated with multidrug-resistant strains of tuberculosis. Kim et al. (2019) and Wang et al. (2015) reported that patients with higher ESR, old age and smear-positive cases had a poorer prognosis in their study group. Surachai et al. (2019) noted that high ESR had a 1.62 increased odds ratio to develop neurological deficit in spinal tuberculosis.

The number of vertebrae involvement was also found to have a significant relationship with the functional outcome. The patients with one unit increase in the number of vertebrae involvement had a $17 \%$ lesser risk of having a poor functional outcome $(p=0.031)$. Sharma et al. (2017) reported an increased chance of neurological recovery in patients with a single functional unit involvement in a study comprising of 312 spinal tuberculosis patients. In comparison, our study population had a mere $12.1 \%$ single level involvement compared to $80.4 \%$ of patients in their study. Upon further analysis of our results, $77.9 \%$ of patients with more than three levels of involvement had undergone surgical treatment compared to $34.9 \%$ of patients with less than three levels of involvement. This explains the good functional outcome associated with the increment of the number of vertebrae involved. Issack et al. (2012) reported that an increased number of vertebrae involved resulted in a higher degree of deformity thus increasing the risk of developing severe neurology.

In this study, a significant difference was observed between the patients with a good functional outcome and the patients without improvement pertaining to the spinal segment involvement $(p=0.007)$. However, the relationship between the number of vertebrae involved and the functional outcome was not significant $(p=0.067)$.

Lesions within the thoracolumbar spinal segment showed a significant relationship with the functional outcome $(p=0.004)$. The patients who had a spinal segment involvement at the thoracolumbar region had 3.31 times higher odds to have a poor functional outcome compared to those with a thoracic segment lesion. This was anticipated as the thoracolumbar junction is a transition zone from the rigid thoracic spine to the mobile lumbar spine. Bony destruction in these regions is known to have a higher incidence of instability (Jalleh et al., 1991). Lesions at the thoracolumbar spine disrupt the mobile lumbar segment, thus limit the rotation and lateral flexion of the spine resulting in a poorer functional outcome, especially in transfer activities (Ghobrial et al., 2014). Comparatively, a study in South Korea comprising of 116 spinal tuberculosis patients concluded that the number of vertebrae involvement and the site of lesion did not affect the prognosis of their patients (Park et al., 2007). Insidious onset of spinal tuberculosis paired with mobile lumbar spine segment may promote worsening of neurology if present (Wang et al., 2016). There is also an increased risk of buckling collapse in lumbar spine lesions as reported by Rajasekar et al (Issack et al., 2012) 
Extension of abscess reflected a nonsignificant difference between patients with a good functional outcome and those without improvement concerning the presence of abscess extension into the spinal cord ( $p=$ 0.292). Similarly, there was no significant difference between the two groups in relation to the presence of abscess extension into the soft tissue $(p=0.143)$. Both types of abscess extensions were also found to have no significant relationship with the functional outcome of patients ( $p=0.293$ and $p=0.147$, respectively).

The overall improvement in the functional outcome was seen in $65.2 \%$ (146 out of 224) of patients in this study population. Potential causes of a poor functional outcome in this study population were logistic difficulties for patients to attend regular rehabilitation therapy, the emergence of drug resistance spinal tuberculosis, the unwillingness of patients to undergo surgical therapy and short follow up period of patients as reported in a Malaysian study of 425 tuberculosis patients (Nissapatorn et al., 2007). Other reported causes of poor prognosis are poor nutritional status, low socioeconomic income, and other concurrent systemic diseases (Cao et al., 2018).

Limitations of this study include the cross-sectional nature of the design, with a short follow up period as the functional outcome may still improve with time. The long-term aim of this paper is to spark interest in the study of prognostic factors, especially in spinal tuberculosis. With an understanding of the prognostic factors involved, a classification or staging system can be developed to help guide surgeons and patient expectations towards the disease.

\section{CONCLUSION}

Despite debilitating functional outcomes associated with spinal tuberculosis, we concluded that $65.2 \%$ of patients from our study population had a good functional recovery. Besides, this study found that increased level of ESR, the number of vertebrae, and thoracolumbar spine involvement were poor prognostic factors of functional outcome in spinal tuberculosis patients. It would be imperative to look for these parameters in spinal tuberculosis patients to initiate aggressive rehabilitation and management to give them their best chance of functional outcome recovery. We also aimed to enhance the clinicians' understanding of functional outcomes and prognostication when treating spinal tuberculosis patients with neurology.

\section{CONFLICT OF INTEREST}

The authors declared that they do not have any conflict of interest in publishing this manuscript.

\section{ACKNOWLEDGEMENTS}

The authors would like to thank all specialists, colleagues and the staff in the Department of Orthopaedic, Traumatology and Rehabilitation, in IIUM Medical Centre, Hospital Queen Elizabeth, Hospital Tawau, and Hospital Lahad Datu, for their contribution, participation and helpful assistance. My heartfelt appreciation to all of the patients who participated in this study.

\section{REFERENCES}

Cao, G., Rao, J. C., Cai, Y., Wang, C., Liao, W., Chen, T., Qin, J., Yuan, H., \& Wang, P. (2018). Analysis of treatment and prognosis of 863 patients with spinal tuberculosis in Guizhou Province. BioMed Research International, 3265735. https://doi.org/10.1155/2018/3265735

Dharmalingam, M. (2004). Tuberculosis of the spine-the Sabah experience. Epidemiology, treatment and results. Tuberculosis (Edinb), $84,24-28$. https://doi.org/10.1016/j. tube.2003.08.008

Ferrer, M. F., Torres, L. G., Ramírez, O. A., Zarzuelo, M. R., \& González, N. D. P. (2011). Tuberculosis of the spine. A systematic review of case series. International Orthopaedics, 36 (2), 221 - 231. https://doi.org/10.1007/s00264-011-1414-4 
Ghobrial, G. M., Maulucci, C. M., Maltenfort, M., Dalyai, R. T., Vaccaro, A. R., Fehlings, M. G., Street, J., Arnold, P. M., \& Harrop, J. S. (2014). Operative and nonoperative adverse events in the management of traumatic fractures of the thoracolumbar spine: a systematic review. Neurosurg Focus, 37 (1), E8. https:// doi.org/10.3171/2014.4.FOCUS1467

Goroh, M. M. D., Rajahram, G. S., Avoi, R., Boogard C. H., William T., Ralph A. P., \& Lowbridge, C. (2020). Epidemiology of tuberculosis in Sabah, Malaysia, 2012 - 2018. Infectious Disease of Poverty, 9, 119. https://doi. org/10.1186/s40249-020-00739-7

Held, M. F. G., Hoppe, S., Laubscher, M., Mears, S., Dix-Peek, S., Zar, H. J., \& Dunn, R. N. (2017). Epidemiology of Musculoskeletal Tuberculosis in an Area with High Disease Prevalence. Asian Spine Journal, 11 (3), 405 - 411. https://doi.org/10.4184/ asj.2017.11.3.405

Issack, P. S., \& Adjei, O. B. (2012). Surgical correction of kyphotic deformity in spinal tuberculosis. International Orthopaedics, 36, 353 - 357. https://doi.org/10.1007/s00264-011-1292-9

Jain, A. K., \& Kumar, J. (2012). Tuberculosis of spine: neurological deficit. European Spine Journal, 22 (4), 624 - 633. https://doi.org/10.1007/ s00586-012-2335-7

Jalleh, R. D., Kuppusamy, I., Mahayiddin, A. A., Yaacob, M. F., Yusuf, N. A., \& Mokhtar, A. (1991). Spinal tuberculosis: A five-year review of cases at the National Tuberculosis Centre. Medical Journal of Malaysia, 46 (3), 269 - 273. https://www.europeanreview. org/wp/wp-content/uploads/1379.pdf

Kim, J. H., Ahn, J. Y., Jeong, S. J., Ku, N. S., Choi, J. Y., Kim, Y. K., Yeom, J. S., \& Song Y. G. (2019). Prognostic factors for unfavorable outcomes of patients with spinal tuberculosis in a country with intermediate tuberculosis burden. Bone Joint J, 101-B (12), 1542 - 1549. https://doi.org/10.1302/0301-620X.101B12. BJJ-2019-0558.R1

Nissapatorn, V., Lim, Y. A. L., Jamaiah, I., Man, C. H., Ilyana, M. Z., Nonaziah, M. Z., Siti H., \& Kuppusamy, I. (2007). Tuberculosis in Malaysia: A continuing surge. Southeast Asian J Trop Med Public Health, 38 (suppl. 1), 231 - 239. http://www.tm.mahidol.ac.th/ seameo/2007-38-suppl-1/38suppl1-231.pdf
Park, D. W., Sohn, J. W., Kim, E. H., Cho, D. I., Lee, J. H., Kim, K. T., Ha, K. Y., Jeon, C. H., Shim, D. M., Lee, J. S., Lee, J. B., Chun, B. S., \& Kim M. J. (2007). Outcome and management of spinal tuberculosis according to severity of disease. Spine, 32 (4), 130 - 135. https://doi. org/10.1097/01.brs.0000255216.54085.21

Sharma, A., Chhabra, H. S., Chabra, T., Mahajan, R., Batra, S., \& Sangondimath, G. (2016). Demographics of tuberculosis of spine and factors affecting neurological improvement in patients suffering from tuberculosis of spine: A retrospective analysis of 312 cases. Spinal Cord, 55 (1), 59 - 63. https://doi. org/10.1038/sc.2016.85

Snider, G. L. (1997). Tuberculosis then and now. A personal perspective on the last 50 years. Ann Intern Med, 126, 237 - 243. https://doi. org/10.7326/0003-4819-126-3-19970201000011

Su, S. H., Tsai, W. C., Lin, C. Y., Lin, W. R., Chen, T. C., Lu, P. L., Huang, P. M., Tsai, J. R., Wang, Y. L., Feng, M. C., Wang, T. P., \& Chen, Y. H. (2010). Clinical features and outcomes of spinal tuberculosis in southern Taiwan. Journal of Microbiology, Immunology and Infection, 43(4):291-300. doi: 10.1016/S1684-1182(10)60046-1.

Surachai, S. J., Wongba, N., \& Leurmprasert, K. (2019). Predictive factors of neurological deficit in patients with spinal tuberculosis. Journal of Orthopaedic Surgery, 27 (3), 1 - 7. https://doi.org/10.1177/2309499019868813

Wang, H., Li, C., Wang, J., Zhang, Z., \& Zhou, Y. (2012) Characteristics of patients with spinal tuberculosis: Seven-year experience of a teaching hospital in southwest China. International Orthopaedics, 36, 1429 - 1434. https://doi.org/10.1007/s00264-012-1511-z

Wang, H., Yang, X., Shi, Y., Zhou, Y., Li, C., Chen, Y., Yu, H., Wang, Q., Li, J., Cheng, J., Zhao, Y., Han, J., \&Xian,g L. (2016). Early predictive factors for lower-extremity motor or sensory deficits and surgical results of patients with spinal tuberculosis.Medicine, 95(34), e4523. https:// doi.org/10.1097/MD.0000000000004523

Wang, W., Zhao, Q., Yuan, Z., Zheng, Y., Zhang, Y., Lu, L., Hou, Y., Zhang, Y., \& Xu, B. (2015). Tuberculosis-associated mortality in Shanghai, China: a longitudinal study. Bull World Health Organ, 93, 826 - 833. https:// doi.org/10.2471/BLT.15.154161

World Health Organization. (2013). Global tuberculosis report 2013. https://apps.who. int/iris/handle/10665/91355 
Clinical, Biochemical and Radiological Factors Affecting the Prognosis of Neurological Deficit Improvement in Spinal Tuberculosis Patients at Hospitals of Sabah

World Health Organization. (2015). The end TB Strategy (WHO/HTM/TB/2015.19). https:// www.who.int/publications/i/item/WHOHTM-TB-2015.19

Yao, Y., Zhang, H., Liu, M., Liu, H., Chu, T., Tang, Y., \& Zhou, Y. (2017). Prognostic factors for recovery of patients after surgery for thoracic spinal tuberculosis. World Neurosurgery, 105, 327 - 331. https://doi.org/10.1016/j. wneu.2017.05.167
Yong, L. N., Ahmedy, F., Yin, K. Y., \& Engkasan, J. P. (2020). Functional outcomes in spinal tuberculosis: A review of the literature. Asian Spine Journal, 15 (3), 381 - 391. https://doi. org/10.31616/asj.2020.0086 
